
\title{
25 Research Square \\ Impacts of Intensive Land use on Soil Biodiversity and Ecosystem Functions in Central China
}

\section{QUANCHAO ZENG}

Huazhong Agriculture University

\section{Yingze Meitang}

Huazhong Agriculture University

Manuel Delgado-Baquerizo

Universidad Pablo de Olavide

\section{Yonghong Wu}

Institute of Soil Science Chinese Academy of Sciences

Wenfeng Tan ( $\nabla$ wenfeng.tan@hotmail.com )

Huazhong Agriculture University https://orcid.org/0000-0002-3098-2928

\section{Research}

Keywords: soil biodiversity, multifunctionality, acidification, citrus plantation, cover cropping

Posted Date: May 11th, 2020

DOI: https://doi.org/10.21203/rs.3.rs-27185/v1

License: (c) (1) This work is licensed under a Creative Commons Attribution 4.0 International License. Read Full License 


\section{Abstract}

Background: The impacts of the conversion of natural to agricultural ecosystem on soil biodiversity and ecosystem functions are still disputable. Here, we compared the soil biodiversity (bacteria and fungi) and ecosystem functions of citrus orchards in different stages of succession (5-30 years) with those in adjacent natural ecosystems. Different management strategies were also considered for one of this stage (15 years).

Results: The results indicate that changes from natural vegetation land to citrus orchards would lead to reduced soil bacterial diversity, as well as significant declines in multiple ecosystem functions associated with $\mathrm{C}$ cycle after 30 years of citrus plantation. However, the functions associated with $\mathrm{N}$ and $\mathrm{P}$ cycle were enhanced by the plantation. Citrus plantation negatively affected the $\mathrm{C}$ cycle by reducing the soil microbial diversity. Reduction in soil bacterial biodiversity was indirectly driven by increased soil acidification resulting from citrus plantation, while wheat straw addition could alleviate the reduction (15year stage). Compared with natural vegetation, citrus plantation also reduced the relative abundance of multiple phylotypes, including Alphaproteobacteria, Deltaproteobacteria, Subgroup_6, Subgroup_4, Anaerolineae and Bacteroidia. The ecological clusters of soil bacteria and fungi were significantly associated with multiple ecosystem functions, suggesting that citrus planting altered multiple ecosystem functions via ecological clusters.

Conclusions: Taken together, our results indicate that soil biodiversity, soil functions and C:N:P coupling are sensitive to the conversion of natural vegetation land to agricultural land, and further suggest that proper management of soil acidification can address some negative impacts of land use conversion on soil biodiversity and functions.

\section{Background}

Conversion from natural to agricultural ecosystem is known to have great impacts on above- and belowground processes and organisms. For example, modern agricultural practices, which are based on industrially produced mineral fertilizers, have been demonstrated to reduce soil carbon content, $\mathrm{N}$ fixation ability and plant diversity $(1,2)$. Agricultural management practices such as soil tillage and fertilization have been found to affect the biomass of arbuscular mycorrhizal fungi (3), earthworms (4), microarthropods (5), and microbial communities (6). Moreover, in general, intensive agricultural practices usually result in simpler soil food webs comprising smaller-bodied organisms and fewer functional groups (7). However, in comparison with that on larger soil organisms and microbial biomass, the effect of conversion from natural to agricultural ecosystem (such as wild forest to orchard) on soil microbial biodiversity (8) and ecosystem functions remains largely unknown. Soil biodiversity plays a key role in regulating the processes that underpin the delivery of ecosystem goods and services in terrestrial ecosystems, and can be altered when natural vegetation lands are changed into agroecosystems. Yet, the mechanism underlying the responses (either positive or negative) of soil biodiversity to cropping has been much less understood, particularly for orchard plantation, as most work investigating the impacts of 
agricultural conversion on microbial communities has been focused on non-woody (e.g., maize, rice or wheat) or small woody crops (vineyards). Understanding the responses of microbial diversity to conversion from natural to agricultural ecosystems is essential for predicting the fate and functions of biodiversity. Another important aspect remaining unexplored is the changes in soil biodiversity and functions in response to agricultural practice in a long temporal scale, as most studies are focused on short-term (months to years) snapshots. For example, a recent study suggested that long-term rice plantation can suppress the diversity of specialized microbes such as $\mathrm{N}$ fixers (Fan et al. 2019). However, how and why soil biodiversity and functions change after decades of cropping remain underexplored.

Herein, we investigated the effects of conversion of natural vegetation land to citrus orchards and longterm (5-30 years) citrus plantation on soil biodiversity and functions. Citrus originated in southeast Asia, and has been cultivated for at least 4000 years $(9,10)$. As a large genus including several major cultivated species, citrus is currently cultivated in more than 140 countries. The total cultivation area of citrus worldwide was approximately 9 million hectares, with a production of 122.3 million tons in 2009, making it one of the most important fruit crops (11). In China, the production of orange increased from 5.61 million tons in 1992 to 38.17 million tons in 2017, showing a nearly 7 -fold increase in 25 years. This rapid growth in production relies heavily on intensive land use. The rhizosphere microbiome is known to have significant effects on citrus growth and health(12). The microbial populations in the rhizosphere can improve the availability of mineral nutrients, production of phytohormones, degradation of phytotoxic compounds and suppression of pathogens $(13,14)$. Therefore, it is significant to clarify the effects of intensive citrus cropping on soil microbiomes to improve citrus health and productivity.

Our hypothesis was that the conversion from natural vegetation land to citrus orchards (1) reduces the diversity of soil bacteria and fungi, (2) declines the soil multifunctionality compared with natural vegetation, and (3) has multiple indirect effects on soil biodiversity and functions via changing the soil properties. To test these hypotheses, we collected soil samples from the orchards with different planting years ( 5,15 and 30 years) at a historical citrus planting site which was converted from natural vegetation land in Central China. We also collected and analyzed soil samples under different managements (15 years). Besides, soil microbial diversity was analyzed and the multifunctionality of the soil associated with $\mathrm{C}, \mathrm{N}$ and $\mathrm{P}$ cycle was calculated. This study may help to facilitate the renovation of old orchards and provide theoretical basis for the sustainable development of orchard plantation.

\section{Methods}

\section{Site description and sampling}

In the past few years, China's citrus industry has been developing very rapidly and the varieties have been updated quickly. Citrus planting has been greatly expanded but at the expense of natural vegetation areas and arable lands. More and more slope lands with natural vegetation have been used for the cultivation of citrus because of the higher economic income compared with the cultivation of other crops such as corn, rice and wheat. Currently, citrus has been the most important fruit crop in China with the highest 
yield and largest planting area. Since the beginning of the century, China's citrus industry has been developing rapidly. The land area for citrus planting has increased from 1.087 million hectares in 1992 to 2.288 million hectares in 2011.

This study was conducted in Zigui County, Hubei province. Citrus is an important economic crop with a long citrus planting history. In the pursuit of the maximum production, excessive application of chemical fertilizers and pesticides has led to serious ecological problems such as soil degradation, soil productivity reduction, and non-point source pollution. The sampling site was in the Zigui Eco-Environmental Monitoring Station ( $31^{\circ} 4^{\prime} \mathrm{N}, 110^{\circ} 41^{\prime} \mathrm{E}$ ), located at Shuitianba Town, Zigui County, Hubei Province, Central China. It situated in a subtropical zone with a monsoonal climate, with a mean annual temperature of $18.2^{\circ} \mathrm{C}$ and a mean annual precipitation of $940.3 \mathrm{~mm}$. The soil type is purple soil derived from purple sandy shale.

We chose 20 citrus orchards (5-year old, 5y; 15-year old, 15y; 30-year old, 30y) and four natural vegetation plots (forests) that were adjacent to the citrus orchards. Three treatments were performed on the 15-year old citrus orchards, including no surface covering (15y-C), surface covering with wheat straw (15y-SM) and surface covering with peanut between rows (15y-PC). All citrus orchards had the same fertilization regimes. Soil sampling was performed in July 2018. In each sampling site, an experimental plot (10 $\mathrm{m} \times$ $10 \mathrm{~m}$, with 16 citrus trees) was established to conduct the soil sampling. All the sampling plots were far from human settlements to eliminate the anthropogenic effects. At each plot, 15 surface soil cores (0$10 \mathrm{~cm}$ soil layers) were collected randomly, and then homogenized and sieved through a 2-mm sieve. The final soil samples were divided into different parts based on the requirements of analysis for different soil properties. One part (approximately $10 \mathrm{~g}$ ) was put in a sterile tube and stored at $-80^{\circ} \mathrm{C}$ for the extraction of soil DNA. The remaining soil was used for the measurement of the basic characteristics.

\section{Edaphic Characteristics}

The soil $\mathrm{pH}$ was determined using a glass $\mathrm{pH}$ meter in a soil water suspension $(1: 2.5, \mathrm{w} / \mathrm{v})$. Soil total carbon (SOC) and nitrogen (TN) were determined with $200 \mathrm{mg}$ air-dried soil through a $0.149 \mathrm{~mm}$ sieve by a element instrument (Vario MAX C/N; Elementar, Germany). Soil nitrate nitrogen (NO3N) and ammonia nitrogen (NH4N) were extracted by $1 \mathrm{~mol} / \mathrm{L} \mathrm{KCl}$ and then determined by a Seal Auto Analyzer3 (15). Soil total phosphorus (TP) was digested by $\mathrm{H}_{2} \mathrm{SO}_{4}-\mathrm{HClO}_{4}$, and determined by melt-molybdenum, antimony and scandium colorimetry. Soil available phosphorus (OlsenP) was extracted with $0.5 \mathrm{~mol} / \mathrm{L} \mathrm{NaHCO}_{3}$, and measured with the same method for measurement of soil TP (16). Soil labile carbon (LOC) was determined by the content of organic carbon oxidized by $333 \mathrm{mmol} / \mathrm{L} \mathrm{K}_{2} \mathrm{MnO}_{4}$. Soil microbial biomass $\mathrm{C}$ (MBC), $N(M B N)$, and $P(M B P)$ were measured by the method of chloroform fumigation as described in previous studies (17-19). All the properties were listed in table S1.

\section{Soil Dna Extraction, Amplification And Sequencing}


Soil genomic DNA was extracted using the PowerSoil kit (MoBio Laboratories, Carlsbad, CA, USA) following the manufacturer's instructions and stored at $-80^{\circ} \mathrm{C}$. After DNA extraction, the quality of DNA was assessed based on the ratios of A260/A230 and A260/A280 using a spectrophotometer. The extracted DNA was stored at $-80^{\circ} \mathrm{C}$ until amplification.

The V3-V4 regions of the bacterial 16S rRNA gene and fungal ITS2 region were amplified using the primers 338F (ACTCCTACGGGAGGCAGCA) and 806R (GGACTACHVGGGTWTCTAAT) (20), and ITS3 (5'GCATCGATGAAGAACGCAGC-3') and ITS4 (5'-TCCTCCGCTTATTGATATGC-3') (21), respectively. PCR amplification was conducted according to the details listed in supporting information as described by previous studies. The purified products were quantified and pooled and then sequenced on the platform of Illumina HiSeq 2500 (Shanghai Personal Biotechnology, Shanghai, China).

\section{Processing Of Sequencing Data}

Initial sequence processing and diversity analysis for both bacterial 16S rRNA and fungal ITS genes were conducted by using the QIIME package. Raw sequences $>150$ bp with an average quality score $>20$ and without ambiguous base calls were quality processed using Qiime (version 1.17). The sequence data were quality filtered; all samples were normalized according to the smallest sequences to ensure that the downstream analyses were performed at the same sequencing depth for all samples. High-quality sequences were clustered into operational taxonomic units (OTUs) with a $97 \%$ similarity using UPARSE (22) (version 7.1, http://drive5.com/uparse/). For 16S RNA OTUs, taxonomy was assigned using UCLUST against the Greengenes database (Version 13_850). For fungal ITS sequences, the taxonomy was assigned by BLAST against the UNITE database. The resultant OTU abundance tables for both primer sets were filtered to remove singletons and rarefied to an even number of sequences per sample to ensure an equal sampling depth (28,204 and 27,000 for $16 S$ rRNA and ITS, respectively). Alpha diversity in each sample was calculated by Shannon index.

\section{Assessment Of Multifunctionality}

Multifunctionality can be used to quantify the provision of multiple ecosystem processes and services simultaneously. Many of these functions, including nutrient cycling (nutrient availability and mineralization), net primary productivity and organic matter decomposition (such as lignin degradation), are driven by microbial communities. To obtain a quantitative multifunctionality index for each site, we first normalized (log-transformation when needed) and standardized each of the 8 functions measured: (1) carbon-related functions, including soil dissolved carbon (DOC), soil labile carbon (LOC), and microbial biomass carbon (MBC); (2) nitrogen-related functions, including nitrate $\mathrm{N}(\mathrm{NO} 3 \mathrm{~N}$ ), ammonium $\mathrm{N}$ (NH4N), microbial biomass $\mathrm{N}(\mathrm{MBN})$; and (3) phosphorus-related functions, including available $\mathrm{P}$ (Olsen $\mathrm{P})$ and microbial biomass $\mathrm{P}$ (MBP). These single standardized ecosystem functions were used to calculate a multifunctionality index using a average approach (23-27). Multifunctionality can provide a direct and easy-to-interpret measure of the ability of different communities to sustain multiple functions 
simultaneously. Before analysis, all individual ecosystem function (EF) variables were standardized by transformation as follows (28):

$E F=[\operatorname{rawEF}-\min (\operatorname{rawEF})] /[\max (\operatorname{rawEF})-\min (\operatorname{rawEF})]$

EF indicates the final (transformed) ecosystem function value, and raw EF represents raw (untransformed) ecosystem function values. The carbon-related ecosystem multifunctionality (CEMF), nitrogen-related ecosystem multifunctionality (NEMF), phosphorus-related ecosystem multifunctionality (PEMF) were calculated using the $\mathrm{C}, \mathrm{N}$ and $\mathrm{P}$ related functions, respectively.

\section{Network Analysis}

Co-occurrence network analysis was conducted to identify the alterations in modules (ecological clusters) of the soil bacteria and fungi using the following protocol $(29,30)$. The correlations were calculated using the relative abundance matrix of soil bacteria and fungi in R 3.6 (31). A co-occurrence was considered as robust if the Spearman's correlation coefficient was greater than 0.6 and the $P$ value was lower than 0.01 (31). This cut-off was biologically meaningful, since we only focused on taxa with significant cooccurrence, which are therefore more likely to interact with each other within a given plant community. The network was visualized in Gephi 0.92 (32). The ecological clusters were identified with the Gephi interactive platform. The relative abundance of each ecological cluster was obtained by averaging the standardized relative abundances (z-scores) of each site (33).

\section{Statistical analysis}

Pearson correlation analysis was used to determine the relationships between microbial groups and environmental factors (soil properties) using SPSS 16.0 (IBM Corporation, Armonk, NY, USA). Random Forest regression modeling was performed to identify the most important microbial taxa (i.e. a large value of Increase in MSE) in predicting the ecosystem functions in R using the packages of randomForest and rfPermute $(34,35)$. The structural equation modeling (SEM) was performed to investigate the effects (direct and indirect) of citrus plantation, soil biodiversity (bacteria and fungi) and soil properties $(\mathrm{pH}$, SOC) on the soil ecosystem functions in Amos 22 (IBM, Chicago, IL, USA) software) (36).

\section{Results}

\section{Impacts of citrus planting on soil microbial diversity and community composition}

The results showed that citrus planting decreased soil bacterial Shannon diversity over time (Fig. 1). By contrast, long term application of wheat straw covering (15 years) significantly enhanced the Shannon diversity of both bacteria and fungi, particularly that of bacteria, reducing the negative impacts of citrus planting on soil biodiversity. The multi regression model showed that soil pH, SOC and DOC have 
significant effects on soil bacterial Shannon diversity, and SOC is the best predictor for the Shannon diversity of soil fungi. Bacterial (ANOSIM: $R=0.998, P<0.001$ ) and fungal (ANOSIM: $R=0.954, P<0.001$ ) communities were distinctly different between different land uses and citrus planting years. The land use conversion showed more obvious effects on bacterial communities than on fungal communities.

\section{Association Between Microbial Diversity And Ecosystem Functions}

Conversion from natural vegetation land to citrus orchards had obvious impacts on multiple functions associated with $\mathrm{C}, \mathrm{N}$ and $\mathrm{P}$ cycle, resulting in functional imbalance (Fig. 1). The land use conversion reduced the $C$ function, while enhanced the $N$ and $P$ function (Fig. 1). On average, the highest CEMF was found in the natural vegetation land. However, compared with natural vegetation, citrus planting improved the NEMF and PEMF.

The results showed that there were significant associations between soil microbial diversity and ecosystem $\mathrm{C}, \mathrm{N}$ and $\mathrm{P}$ multifunctionality (Fig. 2). A positive association between CEMF and soil bacterial diversity $(R=0.45, P=0.027)$, and fungal diversity $(R=0.69, P<0.001)$; a negative association between NEMF and soil fungal diversity $(R=-0.70, P=0.00012)$. Both diversity of soil bacteria $(R=-0.57, P=0.0033)$ and fungi $(R=-0.62, P=0.0012)$ were negatively associated with PEMF. It was also observed that most of the individual functions of soil ecosystem were significantly related to soil microbial diversity (Table S2).

Random Forest regression modeling was performed to identify the most important microbial taxa (i.e. a large value of Increase in MSE) in predicting the ecosystem multifunctionality. Soil fungal diversity, SOC and soil pH were considered as the most important predictors of soil CEMF; while soil bacterial diversity had no significant effects on the CEMF. For NEMF, it was mainly regulated by soil fungal and bacterial diversity; while PEMF was mainly controlled by the soil pH and fungal diversity (Fig. 3).

Structural equation modeling (SEM) was performed to test whether the relationship between microbial diversity and multifunctionality (CEMF, NEMF and PEMF) is maintained when soil pH and SOC are taken into account. The results showed that bacterial diversity had direct negative effects on NEMF and PEMF and a positive effect on CEMF (Fig. 4); and fungal diversity was positively associated with CEMF while negatively associated with NEMF and PEMF. Besides the direct effects, $\mathrm{SOC}$ and $\mathrm{pH}$ had some indirect effects on soil multifunctionality by affecting soil microbial diversity. High SOC significantly enhanced soil bacterial and fungal diversity, while low soil pH would decline fungal diversity, which had great impact on soil multifunctionality (Fig. 4).

\section{Impacts Of Citrus Planting On Soil Microbial Network}

By mcirobial correlation network analysis, three main ecological clusters were identfied, which comprised $\sim 51 \%$ bacterial and $\sim 41 \%$ fungal taxa (Fig. 5). Cluster \#0 was almost found exclusively in natural 
vegetation land, while cluster \#1 and \#2 were exclusively found in citrus planting soils. Overall, the ecological clusters comprised simialr phyla, suggesting that the effects of citrus planting on soil microbial diversity are not phylogenetically conserved; that is, the ecological clusters are not closely related to a single group of microboes, but have impacts on multiple phyla. Six main bacterial and fungal phyla, including Actinobacteria ( 19\%), Proteobacteria ( 11\%), Acidobacteria ( 3.8\%), Ascomycota (47\%), Basidiomycota ( 3.0\%), Chloroflexi ( 2.5\%), and Gemmatimonadetes (1.9\%), contributed to the relative abundance of all ecological clusters. These main phyla had different contributions to the ecological clusters between natural vegetation and citrus planting soils. Fungi (Ascomycota) were more abundant in natural vegetation soils, while bacteria (Proteobacteria and Actinobacteria) were predomiant in citrus planting soils.

\section{Discussion}

This study showed that soil biodiversity, especially bacterial diversity, declines with 30 years of citrus planting, and this decline is associated with soil acidification (Fig. S1). It was also found that specific managements that increase soil $\mathrm{pH}$, such as wheat straw addition, can alleviate the negative impact of crop plantation on soil biodiversity. We also found that the effect of citrus planting on the $\mathrm{C}$ cycle was different from that on $\mathrm{N}$ and $\mathrm{P}$ cycle. Citrus planting promoted the $\mathrm{N}$ and $\mathrm{P}$ cycle but reduced the $\mathrm{C}$ cycle, which was indirectly driven by reduction in soil biodiversity. Together, these findings indicate the importance of maintaining the soil biodiversity and functions in orchard cultivation, and demonstrate some effective management practices to reduce the negative impacts.

\section{Citrus Planting Reduces Soil Microbial Communities}

Conversion from natural to agricultural ecosystems has been considered as the most important driving force to regulate soil microbial communities (37). In this study, citrus planting was found to reduce soil bacterial and fungal diversity in a time dependent manner. Similarly, Berkelmann et al. (2020) found that the conversion from rainforest to rubber and oil palm plantation resulted in a decline in bacterial diversity. These negative effects of the conversion of natural vegetation land to agricultural land on soil bacterial diversity may be ascribed to the homogenization of soil bacteria (38). In an agriculatural ecosystem, the application of organic or inorganic fertilizers would decrease the local bacterial diversity. On the contrary, conversion of tropical forest to agriculture land improved the soil bacterial diversity through an increase in soil pH (39). In our study, citrus planting caused a decline in soil pH, resulting in decreases in soil bacterial diversity. Soil pH has been widely accepted as the most important factor that affects soil bacterial/fungal community composition (Lauber et al., 2009; Rousk et al., 2010; Zeng et al., 2019a; Zeng et al., 2016).

The conversion of natural vegetation land to citrus orchards altered the soil microbial community composition, which is in agreement with the results in previous studies (37). Proteobacteria (Alphaproteobacteria and Deltaproteobacteria) and Acidobacteria (Subgroup_6 and Subgroup_4) were 
negatively influenced by the conversion, which might be due to the decline in soil $\mathrm{pH}$ and SOC. The dramatic increase in soil Actinobacteria indicates its important role in citrus planting soils, because it has been reported that deforested soils has a low abundance Actinobacteria (40). Considering the sharp loss of plant diversity in the agricultural ecosystem, the reduction of soil bacterial communities might be ascribed to the decreases in plant-related microbial groups, such as mycorrhizal fungi and rhizosphere microbes (41). For example, Rhizobiales are highly related to the diversity of aboveground plants, and thus a decrease in plant diversity would lead to corresponding decreases in Rhizobiales $(37,42)$.

Cover cropping has been considered as a promising agricultural practice to improve soil quality, enhance crop yields, and increase soil microbial abundance and diversity (43-45). In this study, we found that the application of wheat straw on the soil surface could enhance the SOC, TN, pH and other properties, which might directly or indirectly increase soil microbial diversity and abundance. These positive effects of straw covering on the composition and diversity of soil microbial community are in line with previous studies $(46,47)$. One possible reason is that the long-term application of straw could relieve soil acidification, which would directly influence the composition of soil bacterial/fungal community. The increase in soil pH due to straw covering enhanced the soil bacterial Shannon index from 10.1 to 10.7 compared with no straw covering within the same planting years (15 years). Similarly, Bu et al. (2020) also repored positive effects of straw returning on the soil bacterial Shannon diversity, which might be attributed to increases in soil organic matter. Therefore, changes in $\mathrm{SOC}$ and $\mathrm{pH}$ together can explain the variations in soil bacterial diversity under the application of straw in this study.

\section{Citrus Planting Reduces Soil Ecosystem Multifunctionality}

The composition and diversity of soil microbial community play central roles in ecosystem multifunctionality in drylands and long-term fertilized soils (23-25). Here, our results suggest that citrus planting significantly alters ecosystem multifunctionality, confirming that land use types have significant impacts on soil ecological functions (48). Compared with natural vegetation, citrus planting increased NEMF and PEMF but reduced CEMF, while the application of wheat straw could enhance the CEMF, implying that the application of straw may alleviate some negative effects of highly intensive citrus planting, such as soil acidification and decreases in soil organic matter, nutrients and soil biodiversity. It has been reported that soil biodiversity has great impacts on soil ecological functions. Any loss in soil biodiversity might decline the ecosystem multifunctionality (25). In this aspect, citrus planting reduces the soil multifunctionality, which might be alleviated by straw application.

It seems that not all studies concluded that microbial diversity has a strong effect on soil multifunctionality. Li et al. (2019) reported that it is fungal richness but not bacterial richness that contributes to multifunctionality in boreal forest soils. In the present study, we also found that soil fungal Shannon diversity explained more variations in NEMF and PEMF than bacterial Shannon diversity. The association between soil bacterial diversity and NEMF was not significant, suggesting that fungi play a dominant role in controlling NEMF. However, fungal communities contributed less to soil 
multifunctionality (CEMF, NEMF and PEMF) than bacterial communities. Most bacterial phyla have been identified as important predictors of soil multifunctionality by Random Forest regression and Pearson correlation analysis. These dominant bacterial phyla participate in the main soil processes related to multiple functions such as $\mathrm{C}, \mathrm{N}$ and $\mathrm{P}$ cycle. For example, members of Patescibacteria, Deinococcus.Thermus, Cyanobacteria and Actinobacteria reduced soil CEMF, while members of Acidobacteria, Chloroflexi and Planctomycetes improved soil CEMF. Fungi mainly affected NEMF, as confirmed by the association between NEMF and the relative abundance of Basidiomycota and Ascomycota. CEMF and NEMF are mainly associated with soil bacterial phyla. These positive or negative associations of bacterial taxa with soil multifunctionality might be ascribed to their life strategies and ecological functions. Citrus planting would alter these main dominant phyla (Fig. S2), leading to variations of soil multifunctionality. These results demonstrate that soil bacterial community composition and diversity largely determine soil multifunctionality in highly intensive citrus planting ecosystem.

Cover cropping is known as an effective way to enhance soil quality. In this study, cover cropping with peanut had significant effects on CEMF and PEMF; while the application of wheat straw improved CEMF. Both methods of surface covering had no significant effects on NEMF. The application of straw would improve the diversity and abundance of microbes that degrade organic matter. Straw decomposition has been considered as an important source of soil organic matter and nutrients, which has indirect impacts on the growth and production of microbes. The higher bacterial and fungal diversity and CEMF in 15y-SM confirmed that long-term application of straw has positive effects on soil biodiversity and multifunctionality. Surface covering with peanut reduced soil biodiversity, but increased soil PEMF.

\section{Citrus Planting Alters Ecological Clusters Of Soil Microbes}

Our results suggest that the conversion of natural vegetation land to agricultural land alters the ecological clusters of soil bacteria and fungi. For example, citrus planting mainly affected ecological cluster \#1 and \#2, while had little effect on cluster \#0, which was dominant in natural vegetation land. Soil Rhizobiales were mainly distributed in ecological cluster \#0, due to the higher plant diversity on natural vegetation land than on agricultural land (37). Similarly, higher abundance of soil Rhizobiales was observed in the forest sites (49). In this study, most members of cluster \#0 preferred a higher soil pH, confirming that soil pH mediates soil microbial community composition in forests (50). The significant association between the diversity of cluster $\# 0$ and CEMF suggests that the main ecological function of cluster \#0 is related to soil $\mathrm{C}$ cycle. Ecological cluster \#1 and \#2 are mainly related to NEMF, including a large number of Burkholderia, which are main $\mathrm{N}$ fixers in soils (2). Soil Burkholderia prefers to utilize the available $\mathrm{N}$ in the soil rather than $\mathrm{N}$ fixation (51), and is more abundant in agricultural soils. Burkholderia belongs to Alphaproteobacteria, which are widely distributed in nutrient-rich soils as a life strategy (copiotrophs) (51). The application of fertilizers for citrus planting may stimulate the growth of these copiotrophic bacteria and enhance their abundance. The significant association between the diversity of cluster \#1 and \#2 and NEMF confirms their ecological functions related $\mathrm{N}$ cycles. 


\section{Conclusions}

Overall, our results suggest that long-term citrus planting strongly reduces the soil microbial diversity and ecological functions related to $\mathrm{C}$ cycle, but enhances those ecological functions associated with $\mathrm{N}$ and $\mathrm{P}$ cycle via soil acidification. Surface covering with straw relieves the soil acidification and contributes to increases in soil bacterial and fungal diversity. Taken together, our results provide novel evidence that citrus planting regulates soil multifunctionality and microbial ecological clusters. Knowing the potential effects of conversion of natural vegetation land to citrus orchards on microbial ecological clusters may help to better predict the influence of highly intensive citrus planting on ecosystem multifunctionality.

\section{Declarations}

\section{Ethics approval and consent to participate}

Not applicable.

\section{Consent for publication}

Not applicable.

\section{Availability of data and material}

Not applicable.

\section{Competing interests}

The authors declare no conflict of interest.

\section{Acknowledgement}

We thanked Jingtao Hou, Xiuhua Chen, Zhe Chen and Lifeng Qiu for their assistance in sampling work. We also thank Shanghai Personal Biotechnology Company for Illumina MiSeq sequencing and data analysis.

\section{Authors' contributions}

WT, MDB, and QZ performed the research. QZ, MDB, and MTY analyzed data and wrote the manuscript. All authors revised and approved the final manuscript.

\section{Funding}

This study was supported by the National Natural Science Foundation of China (41977023 and 41907051) and Project funded by China Postdoctoral Science Foundation (2019M662678).

\section{References}


1. Vitousek PM, Aber JD, Howarth RW, Likens GE, Matson PA, Schindler DW, Schlesinger WH, Tilman DG. Human alteration of the global nitrogen cycle: sources and consequences. Ecological applications. 1997;7:737-50.

2. Fan K, Delgado-Baquerizo M, Guo X, Wang D, Wu Y, Zhu M, Yu W, Yao H, Zhu Y-G, Chu H. Suppressed $\mathrm{N}$ fixation and diazotrophs after four decades of fertilization. Microbiome. 2019;7:143-3.

3. Verbruggen E, Röling WFM, Gamper HA, Kowalchuk GA, Verhoef HA, van der Heijden MGA. Positive effects of organic farming on below-ground mutualists: large-scale comparison of mycorrhizal fungal communities in agricultural soils. New Phytol. 2010;186:968-79.

4. Kuntz M, Berner A, Gattinger A, Scholberg JM, Mäder P, Pfiffner L. Influence of reduced tillage on earthworm and microbial communities under organic arable farming. Pedobiologia. 2013;56:25160.

5. Brennan A, Fortune T, Bolger T. Collembola abundances and assemblage structures in conventionally tilled and conservation tillage arable systems. Pedobiologia. 2006;50:135-45.

6. McDaniel M, Tiemann L, Grandy A. Does agricultural crop diversity enhance soil microbial biomass and organic matter dynamics? A meta-analysis. Ecol Appl. 2014;24:560-70.

7. Tsiafouli MA, Thébault E, Sgardelis SP, de Ruiter PC, van der Putten WH, Birkhofer $K$, Hemerik L, de Vries FT, Bardgett RD, Brady MV, Bjornlund L, Jørgensen HB, Christensen S, Hertefeldt TD, Hotes S, Gera Hol WH, Frouz J, Liiri M, Mortimer SR, Setälä H, Tzanopoulos J, Uteseny K, Pižl V, Stary J, Wolters V, Hedlund K. Intensive agriculture reduces soil biodiversity across Europe. Glob Change Biol. 2015;21:973-85.

8. Dion P. 2010. Towards a new purpose for traditional and other forms of soil knowledge, p 299-316, Soil Biology and Agriculture in the Tropics. Springer.

9. Webber HJ. History and development of the citrus industry. The citrus industry. 1967:1-37.

10. Deng $X$, Yang X, Yamamoto M, Biswas MK. 2020. Domestication and history, p 33-55, The Genus Citrus. Elsevier.

11. Xu Q, Chen L-L, Ruan X, Chen D, Zhu A, Chen C, Bertrand D, Jiao W-B, Hao B-H, Lyon MP, Chen J, Gao S, Xing F, Lan H, Chang J-W, Ge X, Lei Y, Hu Q, Miao Y, Wang L, Xiao S, Biswas MK, Zeng W, Guo F, Cao H, Yang X, Xu X-W, Cheng Y-J, Xu J, Liu J-H, Luo OJ, Tang Z, Guo W-W, Kuang H, Zhang H-Y, Roose ML, Nagarajan N, Deng X-X, Ruan Y. The draft genome of sweet orange (Citrus sinensis). Nat Genet. 2013;45:59-66.

12. Xu J, Zhang Y, Zhang P, Trivedi P, Riera N, Wang Y, Liu X, Fan G, Tang J, Coletta-Filho HD, Cubero J, Deng X, Ancona V, Lu Z, Zhong B, Roper MC, Capote N, Catara V, Pietersen G, Vernière C, Al-Sadi AM, Li L, Yang F, Xu X, Wang J, Yang H, Jin T, Wang N. The structure and function of the global citrus rhizosphere microbiome. Nat Commun. 2018;9:4894.

13. Lugtenberg B, Kamilova F. Plant-growth-promoting rhizobacteria. Annu Rev Microbiol. 2009;63:54156.

14. Fitter A, Gilligan C, Hollingworth K, Kleczkowski A, Twyman R, Pitchford J. Biodiversity and ecosystem function in soil. Funct Ecol. 2005;19:369-77. 
15. Zeng QC, An SS, Liu Y. Soil bacterial community response to vegetation succession after fencing in the grassland of China. Sci Total Environ. 2017;609:2-10.

16. Olsen SR. Estimation of available phosphorus in soils by extraction with sodium bicarbonate. Washington: United States Department of Agriculture; 1954.

17. Vance E, Brookes P, Jenkinson D. Microbial biomass measurements in forest soils: the use of the chloroform fumigation-incubation method in strongly acid soils. Soil Biol Biochem. 1987;19:697702 .

18. Witt C, Gaunt JL, Galicia CC, Ottow JC, Neue H-U. A rapid chloroform-fumigation extraction method for measuring soil microbial biomass carbon and nitrogen in flooded rice soils. Biol Fertil Soils. 2000;30:510-9.

19. Wu J, Joergensen R, Pommerening B, Chaussod R, Brookes P. Measurement of soil microbial biomass $\mathrm{C}$ by fumigation-extraction-an automated procedure. Soil biology biochemistry. 1990;22:1167-9.

20. Hong C, Si Y, Xing Y, Li Y. Illumina MiSeq sequencing investigation on the contrasting soil bacterial community structures in different iron mining areas. Environ Sci Pollut Res. 2015;22:10788-99.

21. Zeng Q, Jia P, Wang Y, Wang H, Li C, An S. The local environment regulates biogeographic patterns of soil fungal communities on the Loess Plateau. Catena. 2019;183:104220.

22. Edgar RC, Haas BJ, Clemente JC, Quince C, Knight R. UCHIME improves sensitivity and speed of chimera detection. Bioinformatics. 2011;27:2194.

23. Chen Q-L, Ding J, Zhu D, Hu H-W, Delgado-Baquerizo M, Ma Y-B, He J-Z, Zhu Y-G. Rare microbial taxa as the major drivers of ecosystem multifunctionality in long-term fertilized soils. Soil Biol Biochem. 2020;141:107686.

24. Delgado-Baquerizo M, Eldridge DJ, Ochoa V, Gozalo B, Singh BK, Maestre FT. Soil microbial communities drive the resistance of ecosystem multifunctionality to global change in drylands across the globe. Ecol Lett. 2017;20:1295-305.

25. Delgado-Baquerizo M, Maestre FT, Reich PB, Jeffries TC, Gaitan JJ, Encinar D, Berdugo M, Campbell $\mathrm{CD}$, Singh BK. Microbial diversity drives multifunctionality in terrestrial ecosystems. Nature Communications. 2016;7.

26. Delgado-Baquerizo M, Trivedi P, Trivedi C, Eldridge DJ, Reich PB, Jeffries TC, Singh BK. Microbial richness and composition independently drive soil multifunctionality. Funct Ecol. 2017;31:2330-43.

27. Soliveres S, Maestre FT, Eldridge DJ, Delgado-Baquerizo M, Quero JL, Bowker MA, Gallardo A. Plant diversity and ecosystem multifunctionality peak at intermediate levels of woody cover in global drylands. Glob Ecol Biogeogr. 2014;23:1408-16.

28. Wang L, Delgado-Baquerizo M, Wang D, Isbell F, Liu J, Feng C, Liu J, Zhong Z, Zhu H, Yuan X. Diversifying livestock promotes multidiversity and multifunctionality in managed grasslands. Proceedings of the National Academy of Sciences. 2019;116:6187-6192.

29. Delgado-Baquerizo M, Reith F, Dennis PG, Hamonts K, Powell JR, Young A, Singh BK, Bissett A. Ecological drivers of soil microbial diversity and soil biological networks in the Southern Hemisphere. 
Ecology. 2018;99:583-96.

30. Delgado-Baquerizo M, Oliverio AM, Brewer TE, Benavent-González A, Eldridge DJ, Bardgett RD, Maestre FT, Singh BK, Fierer N. A global atlas of the dominant bacteria found in soil. Science. 2018;359:320-5.

31. Jiao S, Lu Y. Soil pH and temperature regulate assembly processes of abundant and rare bacterial communities in agricultural ecosystems. Environ Microbiol. 2020;22:1052-65.

32. Bastian M, Heymann S, Jacomy M. Gephi: an open source software for exploring and manipulating networks, p. In, editor.

33. Eldridge DJ, Travers SK, Val J, Wang J-T, Liu H, Singh BK, Delgado-Baquerizo M. Grazing Regulates the Spatial Heterogeneity of Soil Microbial Communities Within Ecological Networks. Ecosystems. 2019. doi:10.1007/s10021-019-00448-9.

34. Archer E. rfPermute: estimate permutation p-values for random forest importance metrics. R package version. 2016;1.

35. Liaw A, Wiener M. Classification and regression by randomForest. R news. 2002;2:18-22.

36. Hooper D, Coughlan J, Mullen MR. Structural equation modelling: Guidelines for determining model fit. Electronic journal of business research methods. 2008;6:53-60.

37. Berkelmann D, Schneider D, Meryandini A, Daniel R. Unravelling the effects of tropical land use conversion on the soil microbiome. Environmental Microbiome. 2020;15:5.

38. Xun W, Xu Z, Li W, Ren Y, Huang T, Ran W, Wang B, Shen Q, Zhang R. Long-term organic-inorganic fertilization ensures great soil productivity and bacterial diversity after natural-to-agricultural ecosystem conversion. J Microbiol. 2016;54:611-7.

39. de Carvalho TS, Jesus EdC, Barlow J, Gardner TA, Soares IC, Tiedje JM, Moreira FMdS. Land use intensification in the humid tropics increased both alpha and beta diversity of soil bacteria. Ecology. 2016;97:2760-71.

40. Mendes LW, de Lima Brossi MJ, Kuramae EE, Tsai SM. Land-use system shapes soil bacterial communities in Southeastern Amazon region. Appl Soil Ecol. 2015;95:151-60.

41. Li Y, Pan F, Yao H. Response of symbiotic and asymbiotic nitrogen-fixing microorganisms to nitrogen fertilizer application. J Soils Sediments. 2019;19:1948-58.

42. Berkelmann D, Schneider D, Engelhaupt M, Heinemann M, Christel S, Wijayanti M, Meryandini A, Daniel R. How rainforest conversion to agricultural systems in Sumatra (Indonesia) affects active soil bacterial communities. Front Microbiol. 2018;9:2381.

43. Daryanto S, Fu BJ, Wang LX, Jacinthe PA, Zhao WW. Quantitative synthesis on the ecosystem services of cover crops. Earth-Sci Rev. 2018;185:357-73.

44. Kim N, Zabaloy MC, Guan K, Villamil MB. Do cover crops benefit soil microbiome? A meta-analysis of current research. Soil Biol Biochem. 2020;142:107701.

45. Poeplau C, Don A. Carbon sequestration in agricultural soils via cultivation of cover crops - A metaanalysis. Agric Ecosyst Environ. 2015;200:33-41. 
46. Bu RY, Ren T, Lei MJ, Liu B, Li XK, Cong RH, Zhang YY, Lu JW. Tillage and straw-returning practices effect on soil dissolved organic matter, aggregate fraction and bacteria community under rice-ricerapeseed rotation system. Agric Ecosyst Environ. 2020;287:8.

47. Wang HH, Li X, Li X, Wang J, Li XY, Guo QC, Yu ZX, Yang TT, Zhang HW. Long-term no-tillage and different residue amounts alter soil microbial community composition and increase the risk of maize root rot in northeast China. Soil Tillage Research. 2020;196:10.

48. Rodrigues JLM, Pellizari VH, Mueller R, Baek K, Jesus ED, Paula FS, Mirza B, Hamaoui GS, Tsai SM, Feigl B, Tiedje JM, Bohannan BJM, Nusslein K. Conversion of the Amazon rainforest to agriculture results in biotic homogenization of soil bacterial communities. Proc Natl Acad Sci USA. 2013;110:988-93.

49. Liu M, Huang H, Bao S, Tong Y. Microbial community structure of soils in Bamenwan mangrove wetland. Scientific reports. 2019;9:1-11.

50. Zeng Q, An S, Liu Y, Wang H, Wang Y. Biogeography and the driving factors affecting forest soil bacteria in an arid area. Sci Total Environ. 2019;680:124-31.

51. Weyens N, van der Lelie D, Taghavi S, Newman L, Vangronsveld J. Exploiting plant-microbe partnerships to improve biomass production and remediation. Trends in biotechnology. 2009;27:591-8.

\section{Figures}



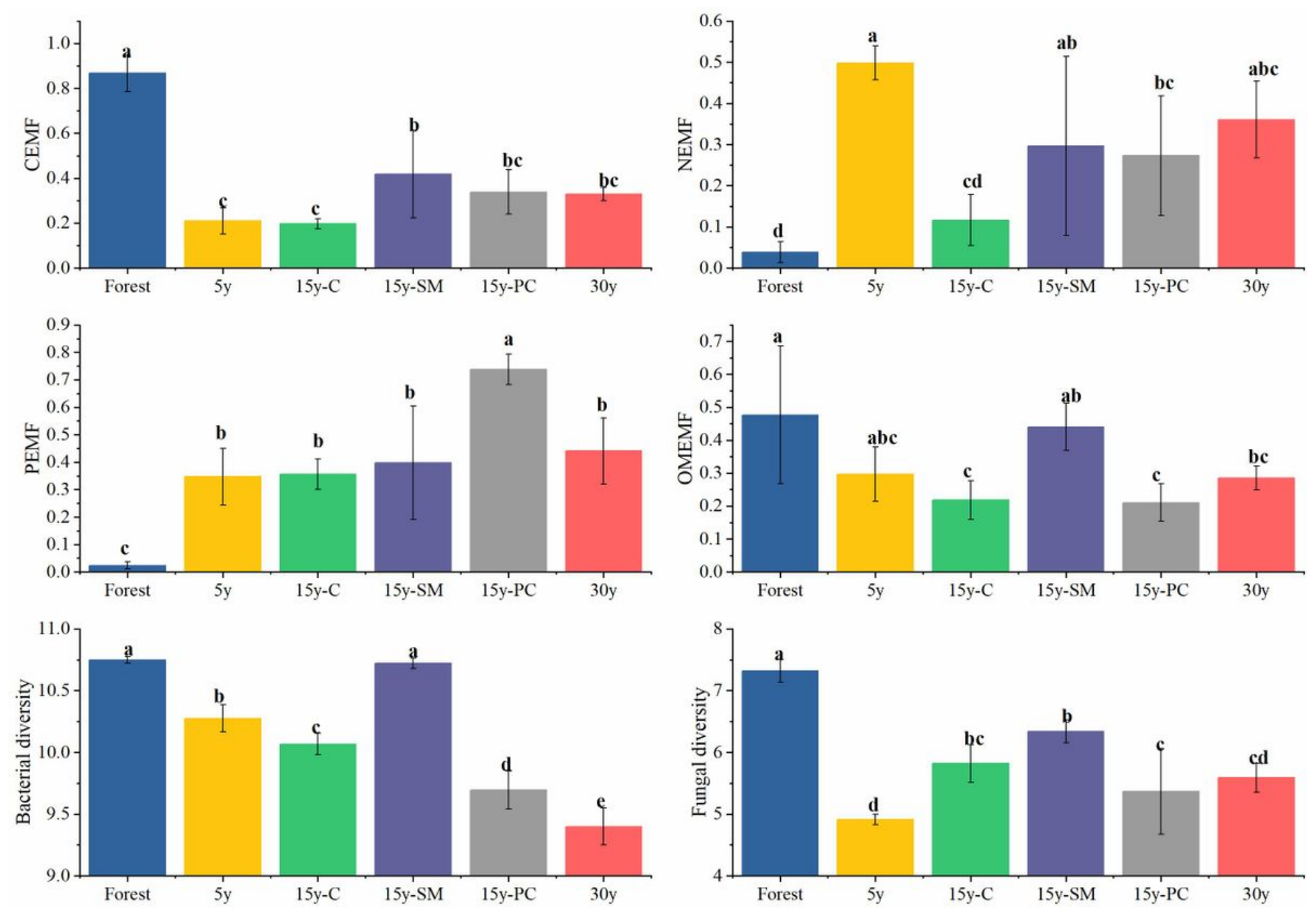

Figure 1

Variations of soil multifunctionality (a, CEMF; b, NEMF; c, PEMF) and microbial diversity (d, bacterial diversity; e, fungal diversity) in soils. CEMF, ecosystem functions related to $C$ cycle; NEMF, ecosystem functions related to $\mathrm{N}$ cycle; PEMF, ecosystem functions related to $\mathrm{P}$ cycle. Different letters indicate significant differences between soil sites. 

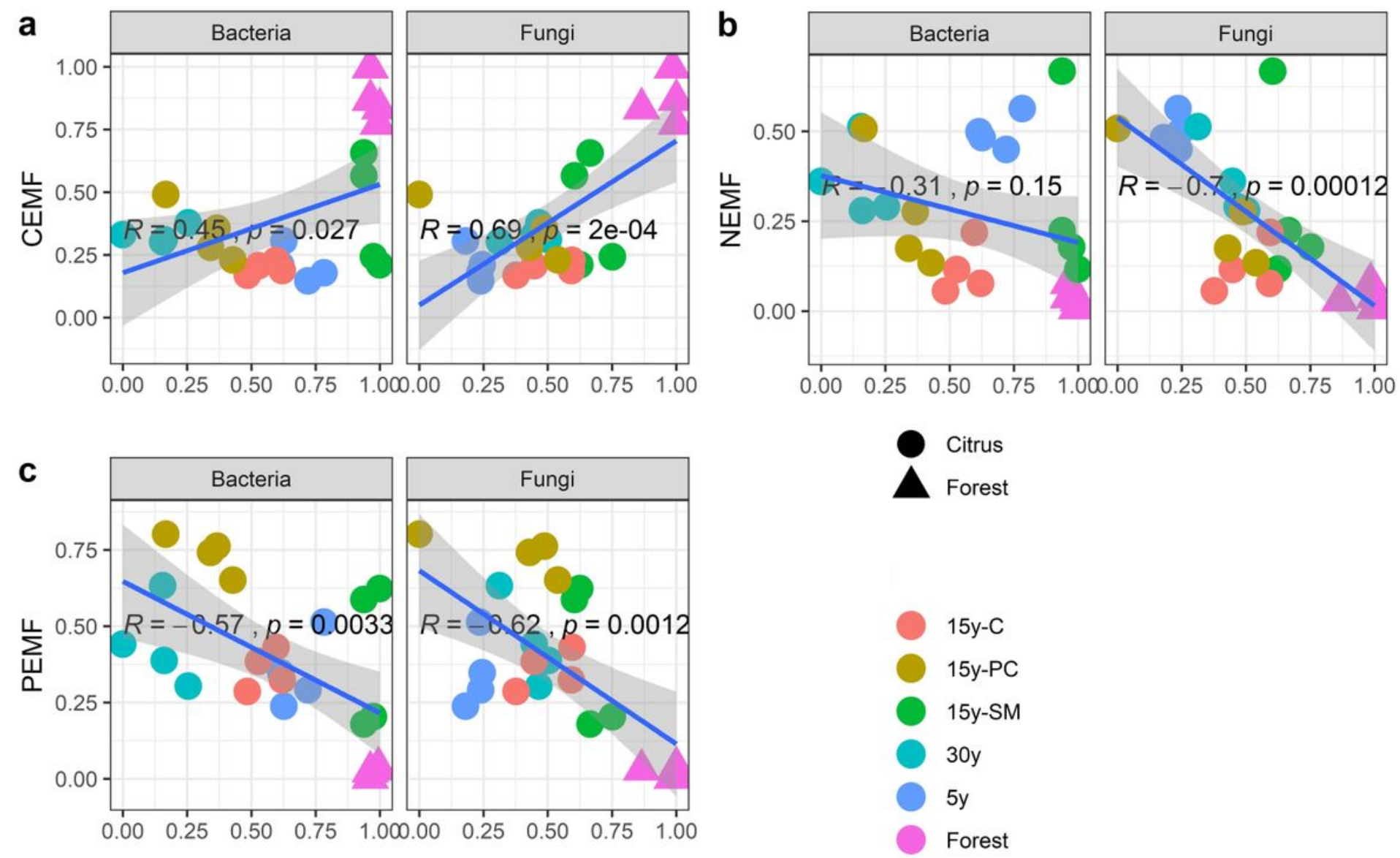

Figure 2

Associations between soil multifunctionality and soil microbial diversity. CEMF, ecosystem functions related to $\mathrm{C}$ cycle; $\mathrm{NEMF}$, ecosystem functions related to $\mathrm{N}$ cycle; $\mathrm{PEMF}$, ecosystem functions related to $\mathrm{P}$ cycle. 


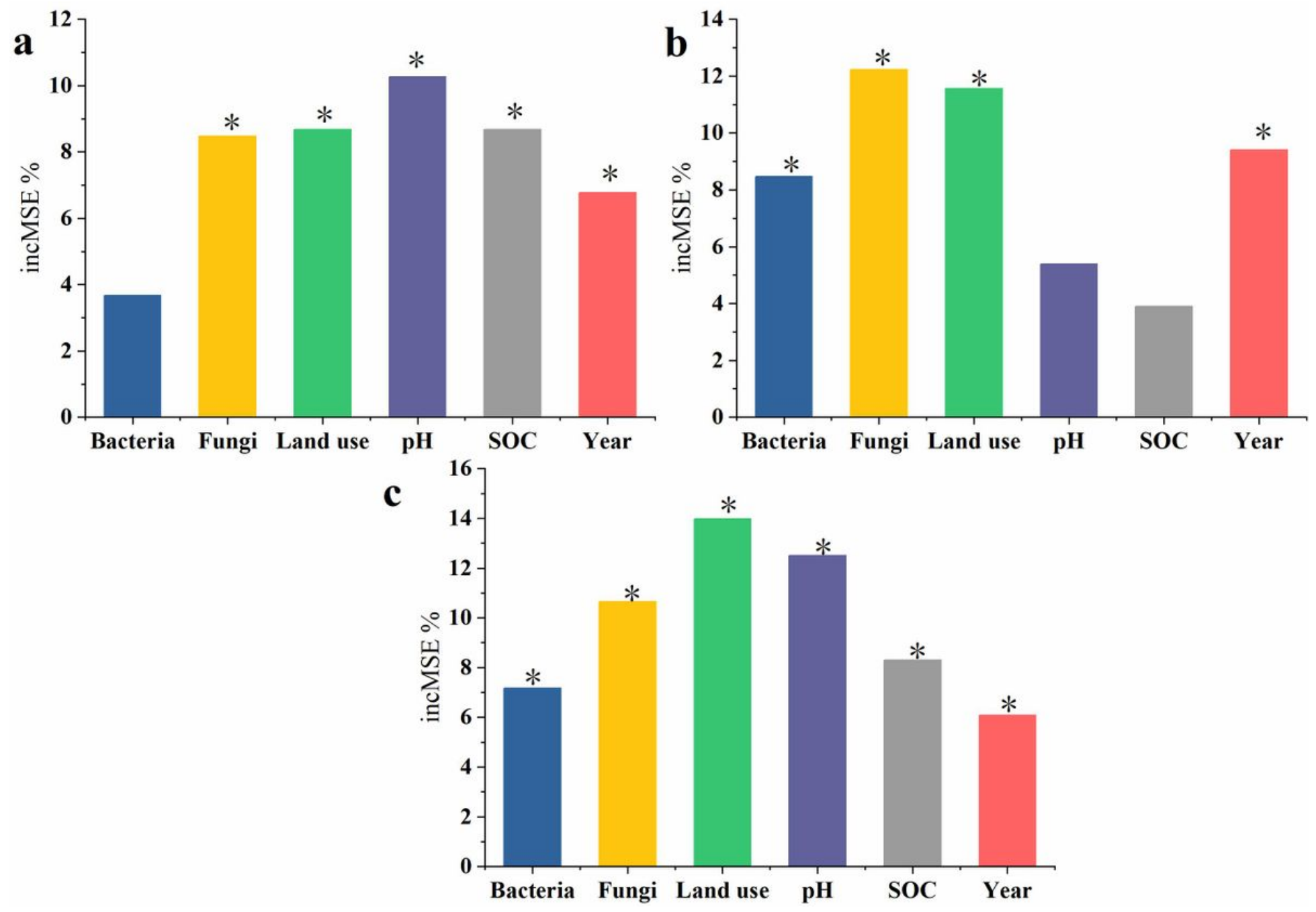

\section{Figure 3}

Predictions of the effects of soil microbial diversity and soil properties on soil multifunctionality (a, CEMF; b, NEMF; c, PEMF) using Random Forest test. CEMF, ecosystem functions related to $\mathrm{C}$ cycle; NEMF, ecosystem functions related to $\mathrm{N}$ cycle; PEMF, ecosystem functions to related $\mathrm{P}$ cycle. 


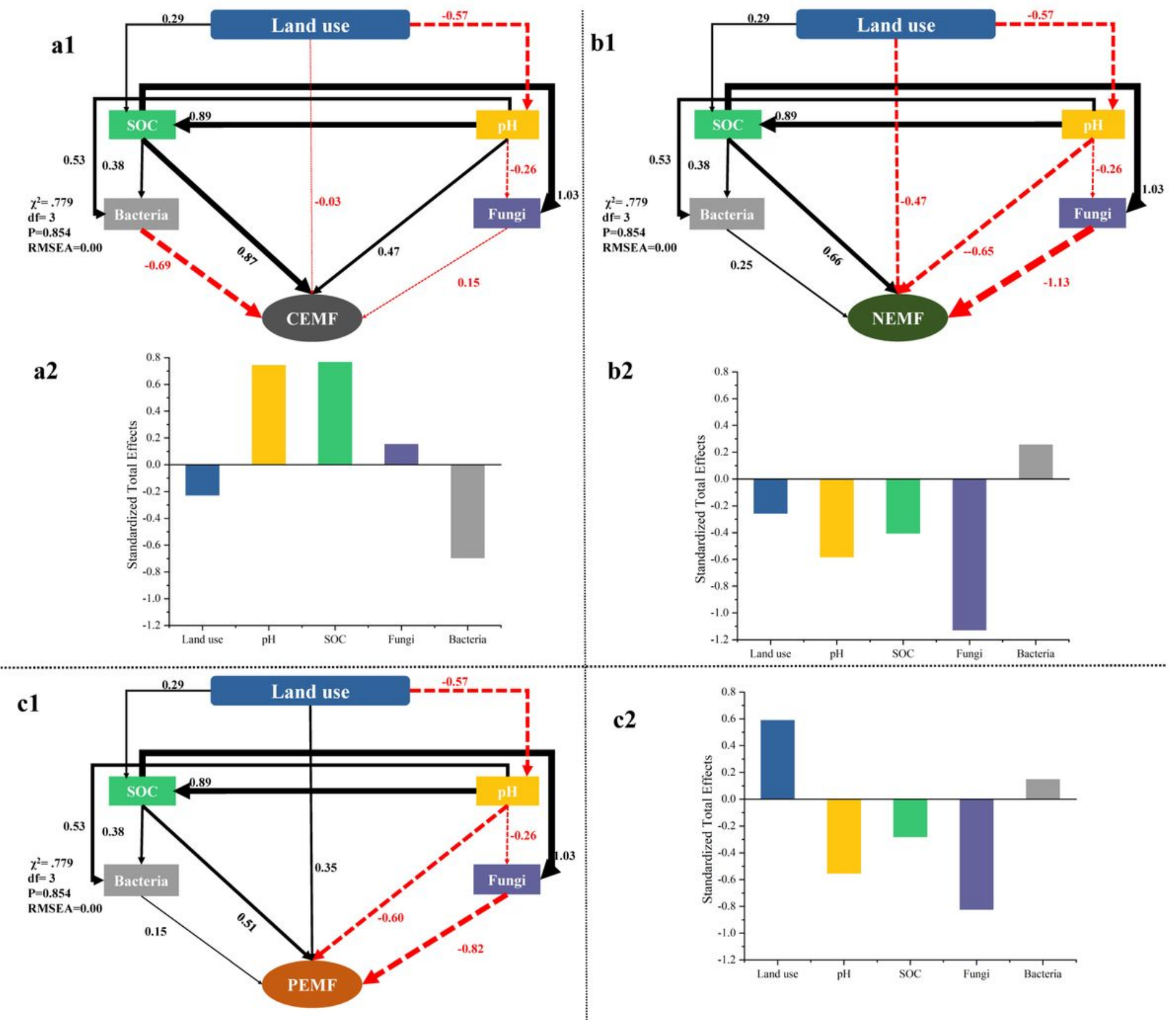

Figure 4

Direct and indirect effects of soil pH, SOC, and biodiversity on ecoystem functions (a1 and a2, CEMF; b1 and b2, NEMF; $c 1$ and c2, PEMF) using SEM. CEMF, ecosystem functions related to $C$ cycle; NEMF, ecosystem functions related to $\mathrm{N}$ cycle; PEMF, ecosystem functions related to $\mathrm{P}$ cycle. 

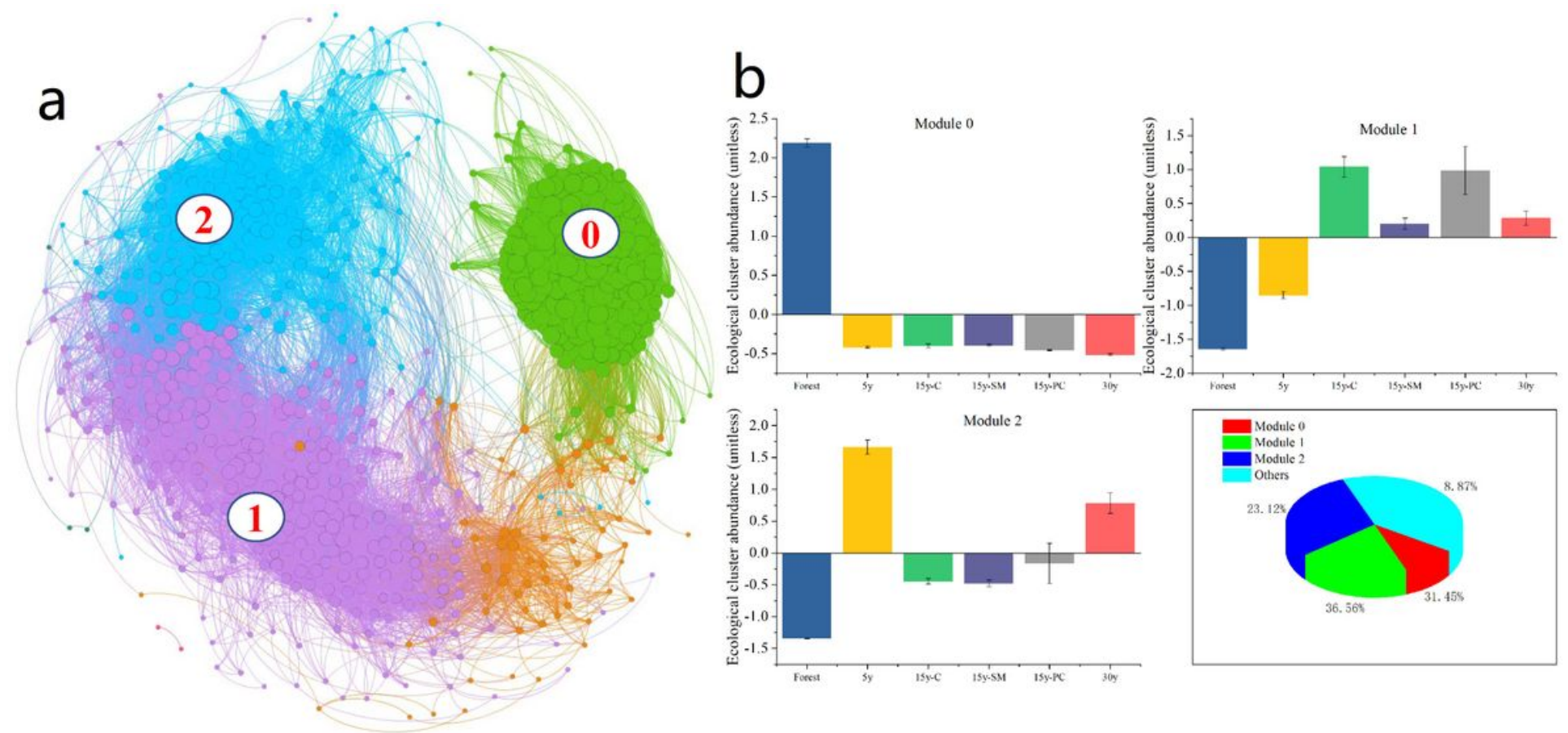

Figure 5

Characteristics of ecological clusters using correlation network analysis (a) and the abundance of each ecological cluster (b).

\section{Supplementary Files}

This is a list of supplementary files associated with this preprint. Click to download.

- SupportingInformation.docx 